\author{
Military Technical College \\ Kobry El-Kobbah, \\ Cairo, Egypt
}

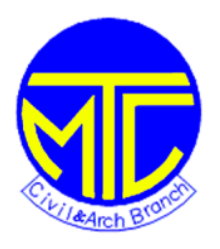

\title{
RHEOLOGY OF FRESH CEMENT PASTE CONTAINNING CHEMICAL ADMIXTURES MATERIALS
}

$8^{\text {th }}$ International Conference on Civil and Architecture

Engineering

ICCAE-8-2010

\section{By}

Prof.Dr.Assem Mostafa Kamal Abdelalim 1

\section{Abstract:}

Understanding the rheology of cement and water is a not a simple task since, the behavior of complicated system various with time and there is still a great deal of work to be done before it is properly understood. Fortunately, fresh cement paste, mortar, at early ages approximate to the Bingham model, and could be tested at two rates of shear, that is ,they require a two point test. All available tests are either empirical or too expensive and could not be used on site, and measure only one parameter. These tests are a single point tests, this means that in each test only one measurement is made, at one rate of shear or under one set of shearing conditions.

In this study we used a new simple technique based on dropping a needle from a constant height. The penetration depth is measured at different circumstances different w/c ratios, types of super plasticizer and different percentage of admixture for two types of cement types of cements (OPC type V) (CEMEX ) and OPC type I (HELWAN). Effect of time of testing after mixing and the effect of agitation of the specimens after 30 minutes as well as the effect of the drop height were also investigated in this study.

This model although simple and cheap and could be performed on site, also proved to be sensitive in monitoring the effect of different water cement ratio, and various percentages of super plasticizer as well as effect of delay of addition of super plasticizer on the penetration depth of the plastic needle.

\section{1- Dean of faculty of engineering}

2- Research for Master Degree. Thesis In Civil Engineering 


\section{Introduction:}

For a full understanding of the flow properties of fresh concrete, first it is necessary to gain a through knowledge of the behavior of pastes consisting of cement and water only.

Cement pastes obviously the most complicated constituent of concrete, consisting as it does of very fine particles under going a chemical reaction, it might be reasonably thought to be primarily responsible for some of the phenomena observed in the concrete behavior. For example, the changes that take place in concrete under vibration might be due to at least partly to a break down of the structure of the paste.

Some of the early work on cement pastes consist either of experiments with apparatus that had been developed primarily for concretes and mortars or for measurements made by simple empirical methods. ${ }^{(1-4)}$

There are two possibilities; the first is by using the methods of soil mechanics and the second by using techniques that have been established for investigating the rheological properties of suspensions. ${ }^{(5-8)}$

The previous work made by Tattersal on cement paste has indicated, that at low rate of shears, the behavior of cement paste followed a Bingham model with yield values and plastic viscosities that were exponent ional functions of water content.

Most recently studies in this field were based on calculating the rheological parameters of cement paste and by using a certain model, the rheological parameters of fresh concrete are measured from that of cement paste, but these were performed by using viscometers or rheometers which are expensive and could not be used on site.

Several investigations that have taken place that took place to define the different types of flow and define the term Rehology. Further investigations were concerned with rhehology of cement pastes ${ }^{(9-12)}$. Further more investigation of the role of fine powder an workability and the effect of partial replacement of cement was and site investigations were also considered in previous studies ${ }^{(13-17)}$. A considerable amount of work has been carried out on the effect of mix design variables up on the two constants (g) and (h) which correspond to the yield and plastic viscosity, on the collection of data on the values necessary for a particular practical job. It may be possible to assign a single figure to each type of job and to and to present the rest of information necessary for production and control of concrete in the form of tables and graphs. The technique adopted in this study would be very helpful in providing this data very easily for the site engineer. 


\section{Experimental Program}

In this section we will discuss the objective and the scope of a three phase program using different cement types in paste mixes with four different types of admixtures. This will be followed by their different characteristics, as well as the test set up used and procedure applied supported with figures showing details of testing.

\section{Phase I :}

This phase focused on the applicability of the needle used in determination of the flow characteristics of two different types of cements through measurements of penetration depth of the plastic needle on cement paste. See Fig (1-4). To reach our goal in this phase, two types of cement were used OPC type I (HELWAN) and SRC type V (CEMEX ), for each type of cement, four different types of super plasticizers were used (Rheobuild 875 type F, Rheobuild 865 type G, Sikament R2002 type G, and Sikament type F). Different Plasticizer/Cement ratio were used $(0.8 \%, 0.9 \%, 1.0 \%, 1.1 \%, 1.2 \%)$. From the obtained results we can measure the degree of compatibility between different types of super plasticizer. Hence, we can determine the optimum dosage that would provide best flow properties. The effect of water/cement ratios only without addition of any superplastisizer $(\mathrm{W} / \mathrm{C}=0.35,0.4,0.45,0.5$, and 0.55$)$ was also considered in this study . See Table (1).

Phase II :

After the development of the optimum dosage obtained from phase I, for each type of cement with respect to each type of super plasticizer, the objective of the experimental program in phase II was to determine the effect of time at $5 \& 10$ and 30 minutes on flow properties which by the way shows the sensitivity of the procedure (drop needle) to measure the flow properties of cement paste. This procedure was followed by retempering after 30 minutes to initiate a break down structure for the cement paste through manual remixing.

In phase II the effect of delay in addition of super plasticizer with $14 \%$ of water to cement paste mix by 5 minutes after initial mixing was also investigated, this procedure was also applied for cement paste mixes with minimum dosage of super plasticizer $(0.8 \%)$.

Phase III:

The objective of the third phase was to study the effect of the height of the needle on the penetration depth of the needle in to cement paste samples; with different W/C $(0.35,0.4,0.45,0.5,0.6)$ at different needle drop heights $(5 \mathrm{~cm}, 10 \mathrm{~cm}$, and $15 \mathrm{~cm})$ measured from the surface of the cement paste. Hence, we will try to find out a relation between potential energy and flow properties of fresh cement paste. 


\section{Table (1) Cement Paste Mix Proportions}

\begin{tabular}{|c|c|}
\hline Mix composition & Quantity \\
\hline Water & $70 \mathrm{gm}$ \\
\hline Cement & $200 \mathrm{gm}$ \\
\hline Admixtures & Based on percent dosage. \\
\hline
\end{tabular}

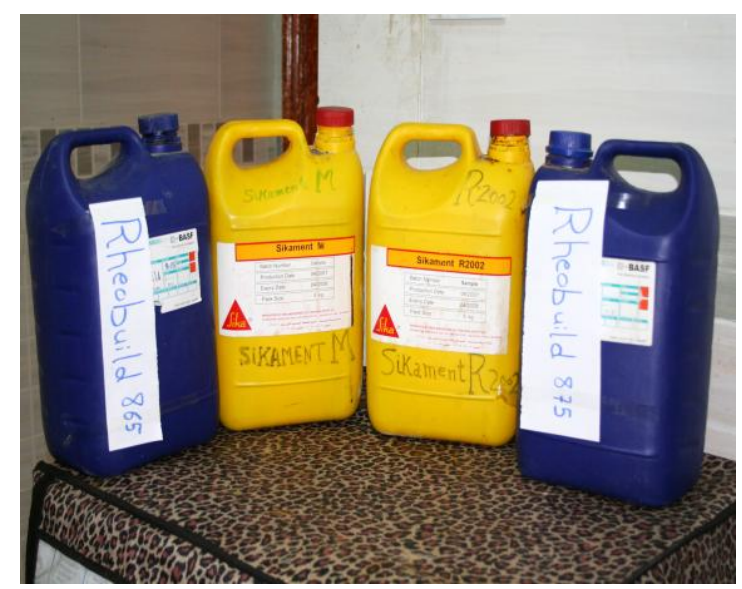

Fig ( 1 ) Four types of chemical admixtures used at experimental work

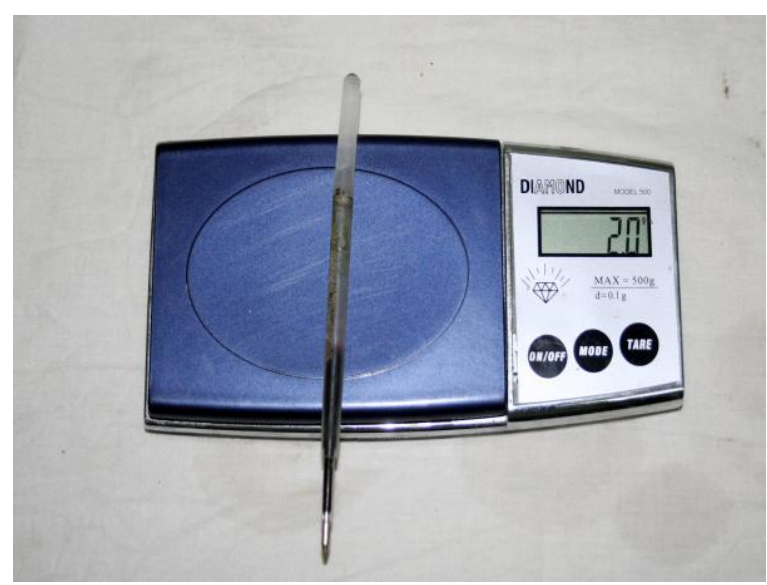

Fig ( 2 ) Measuring Weight of needle. 


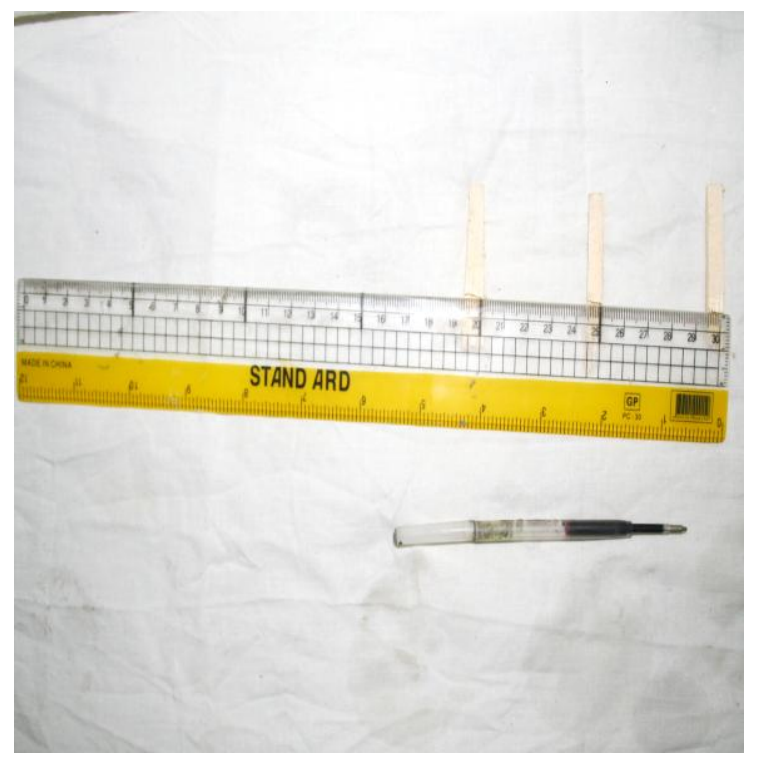

Fig ( 3 ) Needle and Scale used in experimental work

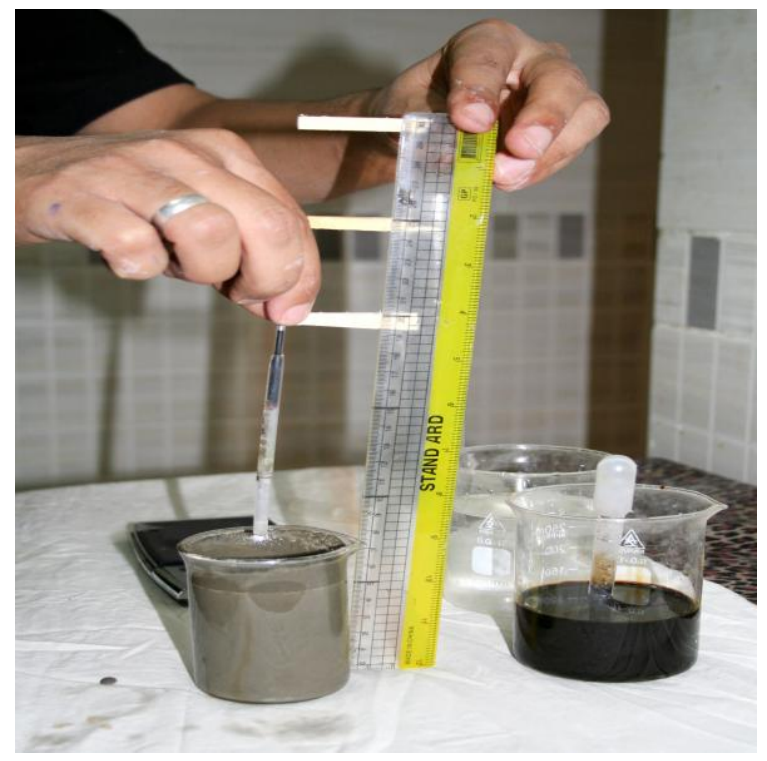

Fig (4 ) Needle Falls in Cement Paste

\section{RESULTS AND DESCUSSION}

In what follows we will discuss the results of penetration depth test method for cement paste mixes under various circumstances. Also we will analyze the scientific test results trying to evaluate those to each others.

\section{Phase I (parametric study):}

Effect of percent dosage of admixtures on different types of cement paste mixes:

Effect of admixtures on OPC type I (Helwan) cement paste:

In this study we will discuss the effect of dosage of different types of admixtures ( Rheobuild 875, Rheobuild 865, Sikament M, and Sikament R2002) on flow properties of cement paste (penetration depth), as mentioned previously, the percent of admixtures under investigation were $(0.8,0.9,1.0,1.1$, and $1.2 \%)$.

For Rheobuild 875 the optimum level of needle penetration was $51 \mathrm{~mm}$ at a plasticizer/ cement ratio $(\mathrm{P} / \mathrm{C})$ of $1.2 \%$, mean while the lowest level of penetration was $41 \mathrm{~mm}$ at a $\mathrm{P} / \mathrm{C}$ ratio of $0.8 \%$.The general trend of this group indicates that the penetration depth value was of smallest value at $\mathrm{P} / \mathrm{C}$ of $0.8 \%$, meanwhile the value increased gradually as $\mathrm{P} / \mathrm{C}$ ratio increased to reach the maximum value at $1.2 \%$.This trend may be attributed to the compatibility of Rheobuild 875 with OPC type I (Helwan). The best result of penetration depth was obtained at $1.2 \%$ dosage. See Table (2) and Fig (5). 
For Rheobuild 865 the optimum level of penetration depth was $39 \mathrm{~mm}$, reached at a plasticizer/ cement ratio (P/C) of $1.2 \%$. Mean while, the lowest level of penetration was $30 \mathrm{~mm}$ at $\mathrm{P} / \mathrm{C}$ ratio of $0.8 \%$. The value was increased gradually as $\mathrm{P} / \mathrm{C}$ ratio increased. The general trend of this group indicates compatible with OPC type I (Helwan) but the flow characteristics did not show the high penetration levels achieved in case of Rheobuild 875.

Sikament R2002, an optimum level of penetration depth of value $41 \mathrm{~mm}$ was reached at a plasticizer/ cement ratio (P/C) of $1.2 \%$, mean while the lowest level of penetration depth of $28 \mathrm{~mm}$ was reached at a $\mathrm{P} / \mathrm{C}$ ratio of $1.0 \%$. This specimen this specimen did show a continuous and stable increase in penetration as $(\mathrm{P} / \mathrm{C})$ was increased.

For Sikament $\mathrm{M}$ is a compatible with OPC type I (Helwan). The optimum level of penetration depth of value $41 \mathrm{~mm}$ was reached at a plasticizer/ cement ratio (P/C) of $1.1 \%$, and remained constant at $1.2 \%$ mean while the lowest level of penetration depth of $32 \mathrm{~mm}$ was reached at P/C ratio of $0.8 \%$.. See Fig (5). Sikament M was similar in performance to Rheobuild 865 , but was more stable and showed a directly proportional relation ship with $(\mathrm{P} / \mathrm{C})$ ratio but did reach the high levels of penetration achieved in Rheobuild 875.

Phase I

Table (2) Peneteration depth results for various types of plasticizer

\begin{tabular}{|l|l|l|l|l|l|l|l|}
\hline & \multicolumn{3}{|l|}{ OPC Type I (HELWAN) } & \multicolumn{2}{l|}{ SRC TYPE V (CEMEX) } \\
\hline Plasticizer/cement & $\begin{array}{l}\text { Rheobuild } \\
875\end{array}$ & $\begin{array}{l}\text { Rheobuild } \\
865\end{array}$ & $\begin{array}{l}\text { Sikament } \\
\text { R 2002 }\end{array}$ & $\begin{array}{l}\text { Sikament } \\
\text { M }\end{array}$ & $\begin{array}{l}\text { Rheobuild } \\
875\end{array}$ & $\begin{array}{l}\text { Rheobuild } \\
865\end{array}$ & $\begin{array}{l}\text { Sikament } \\
\text { R 2002 }\end{array}$ \\
\hline $0.8 \%$ & 41 & 30 & 34 & 32 & 23 & 20 & 24 \\
\hline $0.9 \%$ & 43 & 35 & 30 & 34 & 28 & 20 & 29 \\
\hline $1.0 \%$ & 45 & 34 & 28 & 38 & 25 & 21 & 29 \\
\hline $1.1 \%$ & 49 & 37 & 40 & 41 & 23 & 26 & 29 \\
\hline $1.2 \%$ & 51 & 39 & 41 & 41 & 37 & 26 & 29 \\
\hline Optimum Dose & $1.2 \%$ & $1.2 \%$ & $1.2 \%$ & $1.1 \%$ & $1.2 \%$ & $1.1 \%$ & $1.1 \%$ \\
\hline
\end{tabular}




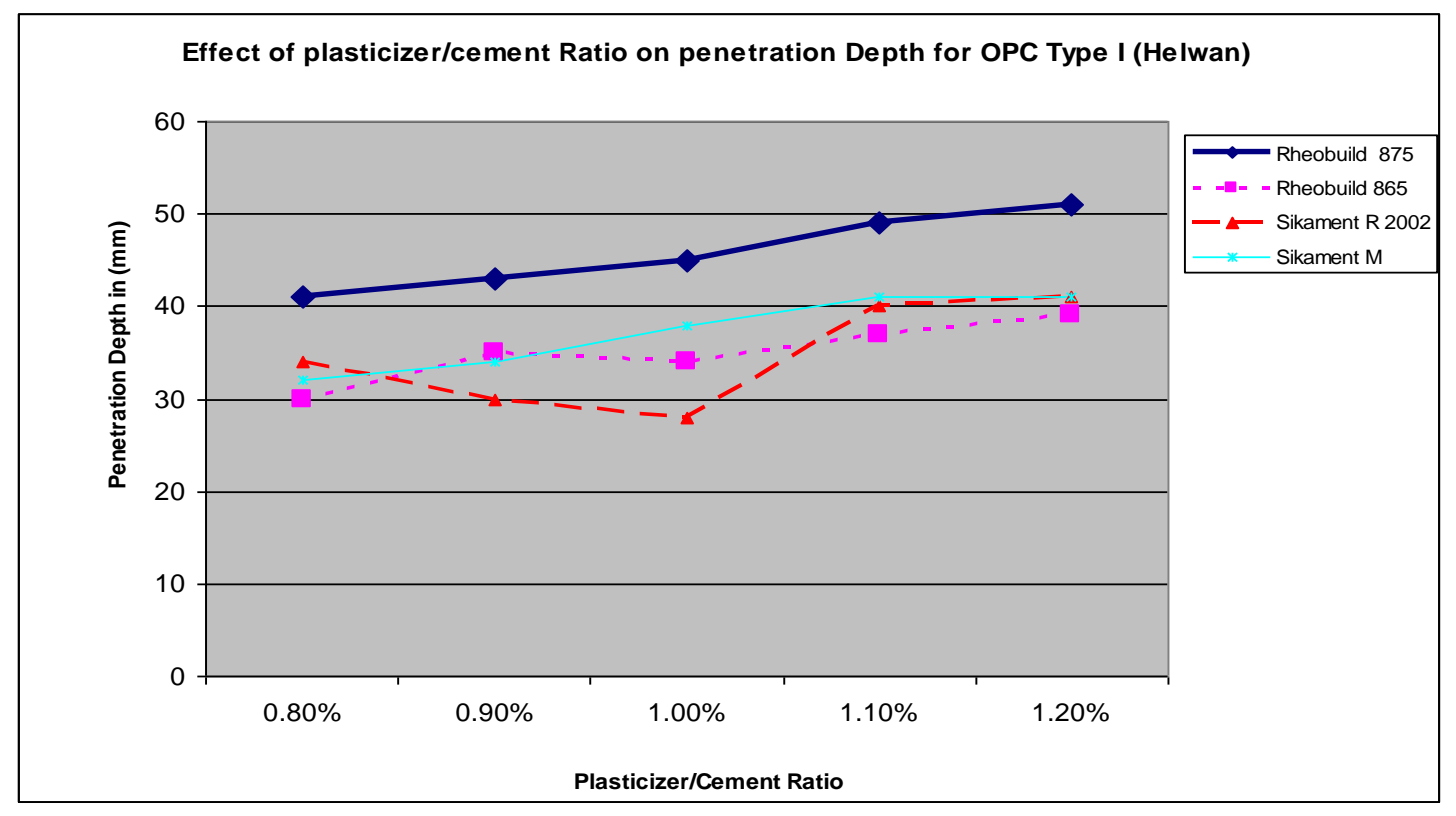

Fig ( 5 ) Effect of plasticizer/cement Ratio on Penetration Depth For OPC Type I (Helwan)

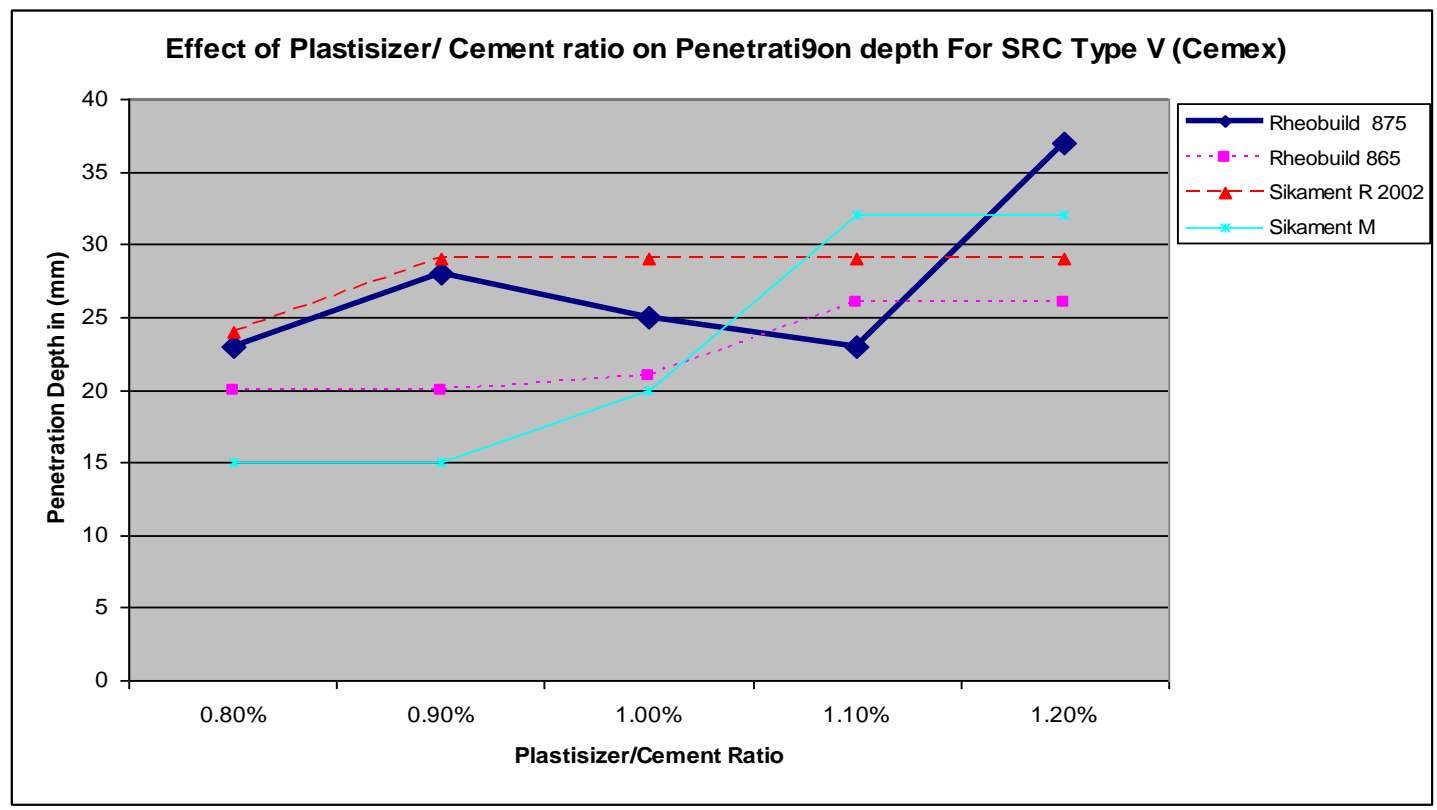

Fig (6) Effect of Plastisizer/ Cement ratio on Penetration depth For SRC Type V (Cemex)

\section{Effect of admixtures on SRC type V (Cemex) cement paste:}

In this study we will discuss the effect of dosage of different types of admixtures ( Rheobuild 875, Rheobuild 865, Sikament M, and Sikament R2002) on flow properties of cement paste (penetration depth), as mentioned previously, the percent of admixtures under investigation were $(0.8,0.9,1.0,1.1$, and $1.2 \%)$. 
For Rheobuild 875 the optimum level of penetration depth $(37 \mathrm{~mm})$ was reached at a plasticizer/ cement ratio $(\mathrm{P} / \mathrm{C})$ of $1.2 \%$. Mean while, the lowest level of penetration depth of $23 \mathrm{~mm}$ was reached at a $\mathrm{P} / \mathrm{C}$ ratio of $0.8 \%$. This group showed highest penetration levels among all groups yet it showed a high degree of instability at levels of $\mathrm{P} / \mathrm{C}$ ratio $1.0 \%$ and $1.1 \%$. This is contrary to the case of using Rheobuild 875 with (OPC) type I Helwan. See Fig (6) and Table (2).

For Rheobuild 865 the highest level of penetration reached was $26 \mathrm{~mm}$ at a plasticizer/ cement ratio $(\mathrm{P} / \mathrm{C})$ of $1.1 \%$ and $1.2 \%$ mean while the lowest level of penetration depth of $20 \mathrm{~mm}$ was reached at $\mathrm{P} / \mathrm{C}$ ratio of $0.8 \%$ and $0.9 \%$, while the value was $21 \mathrm{~mm}$ at $\mathrm{P} / \mathrm{C}$ ratio of $1.0 \%$. The general trend of this group indicates that there is a directly proportional relation ship between penetration and $(\mathrm{P} / \mathrm{C})$, where the smallest value of $20 \mathrm{~mm}$ was obtained at $\mathrm{P} / \mathrm{C}$ ratio of $0.8 \%$ and remain constant at $\mathrm{P} / \mathrm{C}$ of $0.9 \%$, then increased to $21 \mathrm{~mm}$ at $1.0 \%$ and the value was increased suddenly at $\mathrm{P} / \mathrm{C}$ ratio of $1.1 \%$ to reach $26 \mathrm{~mm}$ and remain constant while increasing $\mathrm{P} / \mathrm{C}$ ratio to $1.2 \%$. Although the ultimate penetration level was lower than that encountered when using Rehobuild 875 yet it showed a more stable trend of performance, which indicates that Rheobuild 865 is compatible with SRC type V (Cemex).

For Sikament R2002, the optimum level of penetration depth of value $29 \mathrm{~mm}$ was reached at a plasticizer/ cement ratio $(\mathrm{P} / \mathrm{C})$ of $0.9 \%, 1.0 \%$, and $1.1 \%$. Mean while the lowest level of penetration depth of $24 \mathrm{~mm}$ was reached at a $\mathrm{P} / \mathrm{C}$ ratio of $0.8 \%$. The general trend of this group indicates that Sikament R2002 is compatible with SRC type $\mathrm{V}$ (Cemex) where the results of penetration depth increased gradually as $\mathrm{P} / \mathrm{C}$ ratio increased. The ultimate penetration depth though was not as high as in case of Rehobuild 875 and Rehobuild 865.

For Sikament M, the optimum level of penetration depth of value $32 \mathrm{~mm}$ was reached at a plasticizer/ cement ratio $(\mathrm{P} / \mathrm{C})$ of $1.1 \%$. Mean while the lowest level of penetration depth of $15 \mathrm{~mm}$ was reached at a $\mathrm{P} / \mathrm{C}$ of $0.9 \%$. The general trend of this group indicates that the penetration depth value increased as $\mathrm{P} / \mathrm{C}$ ratio increased. Sikament $\mathrm{M}$ is compatible with SRC type V (Cemex). The performance of this group showed a directly proportional relation ship between penetration depth and (Plasticizer/Cement) ratio. The ultimate penetration level was higher than that encountered Rehobuild 865 and Sikament R2002, and it showed a more stable performance compared to Rehobuild 875.

The General performance of subgroups using ( SRC ) cement showed lower levels of penetration compared to specimens using (OPC). 


\section{Effect of W/C ratio on flow properties of cement paste:}

\section{Effect of $w / c$ ratio on OPC type I (Helwan) cement paste:}

In this study we will discuss the effect of w/c ratio on flow properties of cement paste (penetration depth), as mentioned previously, the w/c ratios under investigation were $(0.35,0.4,0.45,0.5$, and 0.55$)$ no plasticizer was used in this group. For OPC type I (Helwan), the smallest value of penetration depth of $14 \mathrm{~mm}$ was obtained at w/c ratio of 0.35 which is the minimum ratio used in the test, while the largest value of penetration depth of $55 \mathrm{~mm}$ was reached at w/c ratio of 0.55 . The general trend of this group indicates that the penetration depth value was increased as the w/c ratio increased. This trend may indicates that there was a direct relation between $\mathrm{w} / \mathrm{c}$ ratio and value of penetration depth and the relation was approximately linear. See Fig (7).

\section{Effect of $w / c$ ratio on SRC type V (Cemex) cement paste:}

The general trend indicates the existence of the same proportionality mentioned above. For SRC type V (Cemex), the smallest value of penetration depth of $14 \mathrm{~mm}$ was obtained at w/c ratio of 0.35 which was the minimum ratio used in the test, while the largest value of penetration depth of $63 \mathrm{~mm}$ was reached at w/c ratio of 0.55 . The general trend of this group indicates that the penetration depth value was increased as the w/c ratio increased. Comparison between SRC and OPC indicates that at low levels of W/C 0.35-0.4 the performance of both groups was very similar, but at high levels of W/C OPC was more sensitive to the increase in $\mathrm{W} / \mathrm{C}$, reaching higher levels of penetration which indicates higher levels of flowability. 


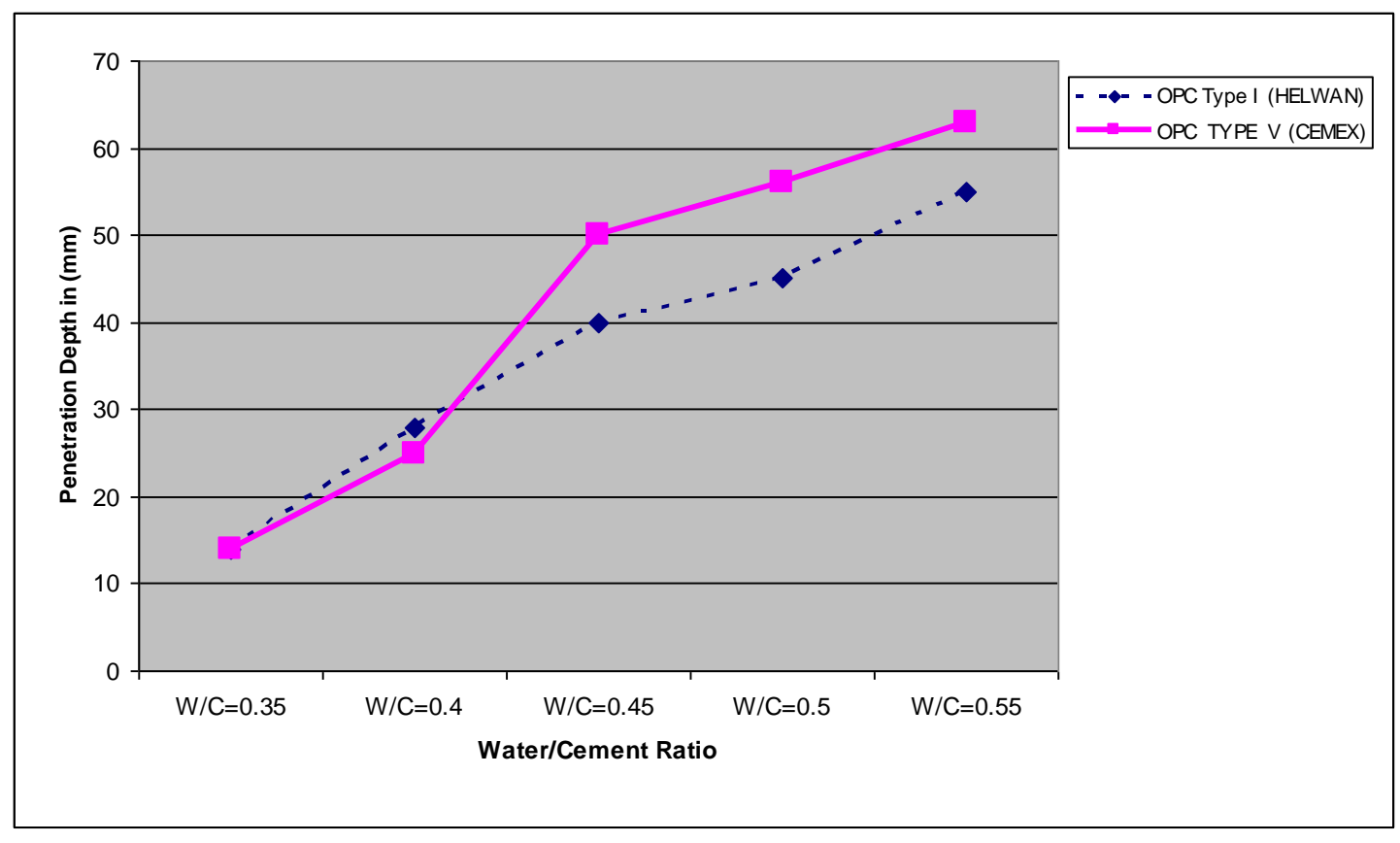

Fig (7)Effect of w/c on the penetration depth for different types of cement

Phase II (parametric study):

Effect of time (5min, 10min, and $30 \mathrm{~min})$ on penetration depth:

Effect of time on OPC Type I (Helwan) cement paste:

For Rheobuild 875, the optimum P/C ratio for this subgroup was $1.2 \%$. Penetration depth value of $51 \mathrm{~mm}$ at initial testing was registered, this value was decreased as the time increased. After 5minutes of initial mixing and penetration value decreased to 29 $\mathrm{mm}$ and maintains decrease till it reaches $16 \mathrm{~mm}$ after 10 minutes. after 30 minutes, penetration depth decreased to a minimum value of $4 \mathrm{~mm}$ at 30minutes.

For Rheobuild 865, the same trend mentioned previously for Rheobuild 875, was observed for this subgroup as well. The optimum P/C ratio was $1.2 \%$, which corresponded to penetration depth value of $39 \mathrm{~mm}$ at initial testing, this value decreased as the time increased, where the penetration depth reached $10 \mathrm{~mm}$ after 5 minutes and $3 \mathrm{~mm}$ after 10 minutes of initial mixing and reaching a minimum value of $0 \mathrm{~mm}$ at 30minutes. See Table (3) and Fig (8).

For Sikament R2002, the optimum P/C ratio was $1.1 \%$ which corresponded to penetration depth value of $41 \mathrm{~mm}$ at initial testing, this value was decreased as the time increased, where the value was equal $34 \mathrm{~mm}$ after 5minutes of initial mixing and still decease till reaches $22 \mathrm{~mm}$ after 10 minutes of initial mixing and reaches the minimum value of $6 \mathrm{~mm}$ at 30 minutes after initial mixing.

For Sikament $\mathrm{M}$, the optimum $\mathrm{P} / \mathrm{C}$ ratio was $1.2 \%$ which corresponded to penetration depth value of $41 \mathrm{~mm}$ at initial testing, this value decreased as the time increased, where 
the value was equal to $21 \mathrm{~mm}$ after 5 minutes of initial mixing and continues to decrease till it reaches $16 \mathrm{~mm}$ after10minutes and reaches a minimum value of $9 \mathrm{~mm}$ after 30minutes. The rate of decrease in penetration depth (flowability) for this group was the lowest among all groups.

The general trend indicates that, the value of penetration depth decreases as the time increases, this may be attributed to the fact that as the time increase, the hydration process increase, also loss of water due to evaporation and chemical reaction which result in decrease in flow ability of cement paste mix, in addition to the fact that temporary effectiveness of super plasticizer starts to disappear.

\section{Effect of time on SRC Type V(Cemex) cement paste:}

For Rheobuild 875 , the optimum $\mathrm{P} / \mathrm{C}$ ratio was $1.2 \%$ which corresponded to penetration depth value of $37 \mathrm{~mm}$ at initial testing, this value decreased to $28 \mathrm{~mm}$ after 5 minutes of initial mixing and reaches $7 \mathrm{~mm}$ after10minutes. After 30 minutes penetration depth reaches $1 \mathrm{~mm}$. See Table (3) and Fig (9).

For Rheobuild 865 , the optimum P/C ratio was $1.0 \%$ which corresponded to penetration depth value of $29 \mathrm{~mm}$ at initial testing, this value decreased as the time increased, and reaches a minimum value of $1 \mathrm{~mm}$ at 30 minutes. The general trend for this group was similar to that of Rheobuild 875 but with lower levels of penetration.

Sikament R2002, had an optimum P/C ratio 0.9\% which corresponded to penetration depth value of $30 \mathrm{~mm}$ at initial testing, this value was decreased as the time increased, where the value was equal $22 \mathrm{~mm}$ after 5 minutes of initial mixing and still decreases till reaches $4 \mathrm{~mm}$ after10minutes of initial mixing and reaches the minimum value of $1 \mathrm{~mm}$ at 30minutes after initial mixing.

For Sikament $\mathrm{M}$, the optimum $\mathrm{P} / \mathrm{C}$ ratio was $1.1 \%$ which corresponded to penetration depth value of $32 \mathrm{~mm}$ at initial testing, this value was decreased as the time increased, where the penetration value was equal $12 \mathrm{~mm}$ after 5 minutes of initial mixing and still decreases, till it reaches $7 \mathrm{~mm}$ after10minutes of initial mixing and reaches a minimum value of $3 \mathrm{~mm}$ after 30 minutes after. Rate of decrease in penetration depth for this group was the lowest among all groups.

Table (3)Penetration depth for various types of cement at different time intervals

\begin{tabular}{|l|l|l|l|l|l|l|l|l|}
\hline & \multicolumn{9}{|l|}{ OPC Type I (HELWAN) } \\
\hline Time & $\begin{array}{l}\text { Rheobuild } \\
875\end{array}$ & $\begin{array}{l}\text { Rheobuild } \\
865\end{array}$ & $\begin{array}{l}\text { Sikament } \\
\text { R 2002 }\end{array}$ & $\begin{array}{l}\text { Sikament } \\
\text { M }\end{array}$ & $\begin{array}{l}\text { Rheobuild } \\
875\end{array}$ & $\begin{array}{l}\text { Rheobuild } \\
865\end{array}$ & $\begin{array}{l}\text { Sikament } \\
\text { R 2002 }\end{array}$ & $\begin{array}{l}\text { Sikamen } \\
\text { M }\end{array}$ \\
\hline 1 minute & 51 & 39 & 41 & 41 & 37 & 29 & 30 & 32 \\
\hline 5 minutes & 29 & 10 & 34 & 21 & 28 & 14 & 22 & 12 \\
\hline 10 minutes & 16 & 3 & 22 & 16 & 7 & 6 & 4 & 7 \\
\hline 30 minutes & 4 & 0 & 6 & 9 & 1 & 1 & 1 & 3 \\
\hline $\begin{array}{l}30 \text { minutes } \\
+ \\
\text { Retemixing }\end{array}$ & 14 & 10 & 18 & 21 & 9 & 8 & 7 & 9 \\
\hline
\end{tabular}




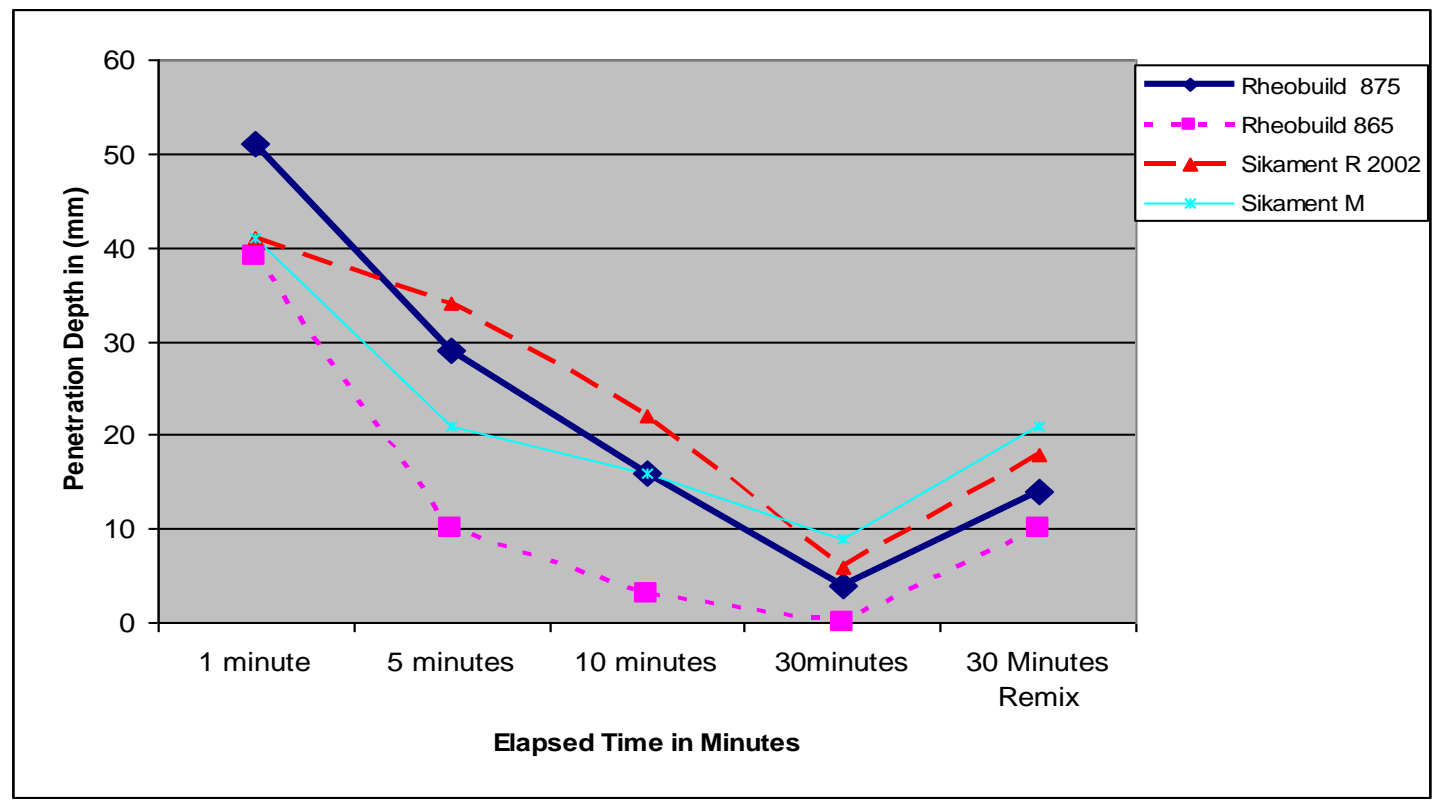

Fig ( 8 ) Effect of Time on penetration depth for OPC Type I (HELWAN)

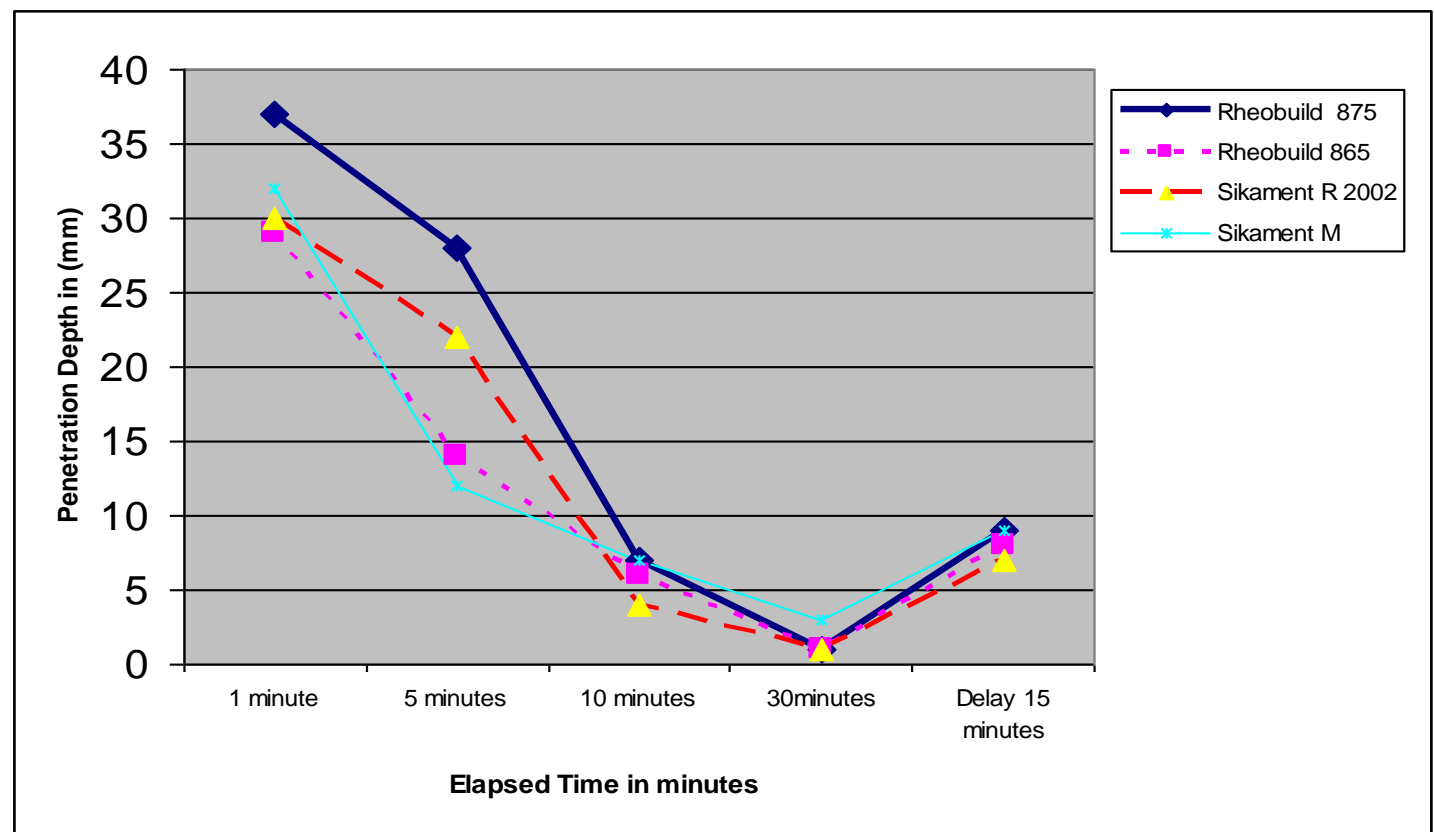

Fig ( 9 ) Effect of Time on penetration depth for SRC TYPE V (CEMEX) Effect of Retempering on penetration depth: 


\section{Effect of Retempering after 30minutes on OPC Type I (Helwan) cement paste:}

For Rheobuild 875, the optimum P/C ratio was $1.2 \%$ which corresponded to penetration depth value of $51 \mathrm{~mm}$ at initial testing, this value decreased as the time increased till it reached a minimum value of $4 \mathrm{~mm}$ at 30minutes after initial mixing. After this stage as we performed retempering or agitation for cement paste mix by 25 revolution by a metal rod then the value of penetration depth increases again to a value of $14 \mathrm{~mm}$. See Fig (10) For Rheobuild 865 , the optimum P/C ratio was $1.2 \%$ which corresponded to penetration depth value of $39 \mathrm{~mm}$ at initial testing, this value reached a minimum value of $0 \mathrm{~mm}$ at 30 minutes after initial mixing after this stage as we made retempering or agitation for cement paste mix by 25 revolution by a metal rod then the value of penetration depth increases again to a value of $10 \mathrm{~mm}$.

For Sikament R2002, the optimum P/C ratio was $1.1 \%$ which corresponded to penetration depth value of $41 \mathrm{~mm}$ at initial testing, this value was decreased as the time increased till reach the minimum value of $6 \mathrm{~mm}$ at 30 minutes after initial mixing after this stage as we made retempering or agitation for cement paste mix by 25 revolution by a metal rod then the value of penetration depth increases again to a value of $18 \mathrm{~mm}$.

For Sikament $\mathrm{M}$, the optimum $\mathrm{P} / \mathrm{C}$ ratio was $1.2 \%$ which corresponded to penetration depth value of $41 \mathrm{~mm}$ at initial testing, this value was decreased as the time increased till reach the minimum value of $9 \mathrm{~mm}$ at 30 minutes after initial mixing, after this stage as we made retempering or agitation for cement paste mix by 25 revolution by a metal rod then the value of penetration depth increases again to a value of $21 \mathrm{~mm}$.

The general trend indicates that, the value of penetration depth increases again as cement paste is subjected to agitation, the reason for this is the break down structure of the cement paste. The value of penetration depth after agitation for most of the cases was more than the value of penetration at 10 minutes after initial mixing.

\section{Effect of Retempering after 30minutes on SRC Type V(Cemex) cement paste:}

For Rheobuild 875 , the optimum P/C ratio was $1.2 \%$ which corresponded to needle penetration depth of $37 \mathrm{~mm}$ at initial testing, this value decreased as the time increased to reach a minimum of $1 \mathrm{~mm}$ at 30minutes after initial mixing. After retempering or agitation for cement paste mix by 25 revolution by a metal rod, then the value of penetration depth increased again upto 9mm. See Fig (10). See Table (3).

For Rheobuild 865 , the optimum P/C ratio was $1.0 \%$ which corresponded to penetration depth value of $29 \mathrm{~mm}$ at initial testing; this value decreased as the time increased, to reach a minimum value of $1 \mathrm{~mm}$ at 30minutes after initial mixing. Retempering increased the value of penetration depth increases again to a $8 \mathrm{~mm}$.

For Sikament R2002, the optimum P/C ratio was $0.9 \%$ which corresponded to penetration depth value of $30 \mathrm{~mm}$ at initial testing, this value was decreased as the time increased till reaches the minimum value of $1 \mathrm{~mm}$ at 30 minutes after initial mixing after 
this stage as we made retempering. the value of penetration depth increased again to a value of $7 \mathrm{~mm}$.

For Sikament $\mathrm{M}$, the optimum $\mathrm{P} / \mathrm{C}$ ratio was $1.1 \%$ which corresponded to penetration depth value of $32 \mathrm{~mm}$ at initial testing, this value was decreased as the time increased to reach a minimum value of $3 \mathrm{~mm}$ at 30 minutes after initial mixing after this stage as we made retempering or agitation for cement paste mix by 25 revolution by a metal rod then the value of penetration depth increases again to a value of $9 \mathrm{~mm}$.

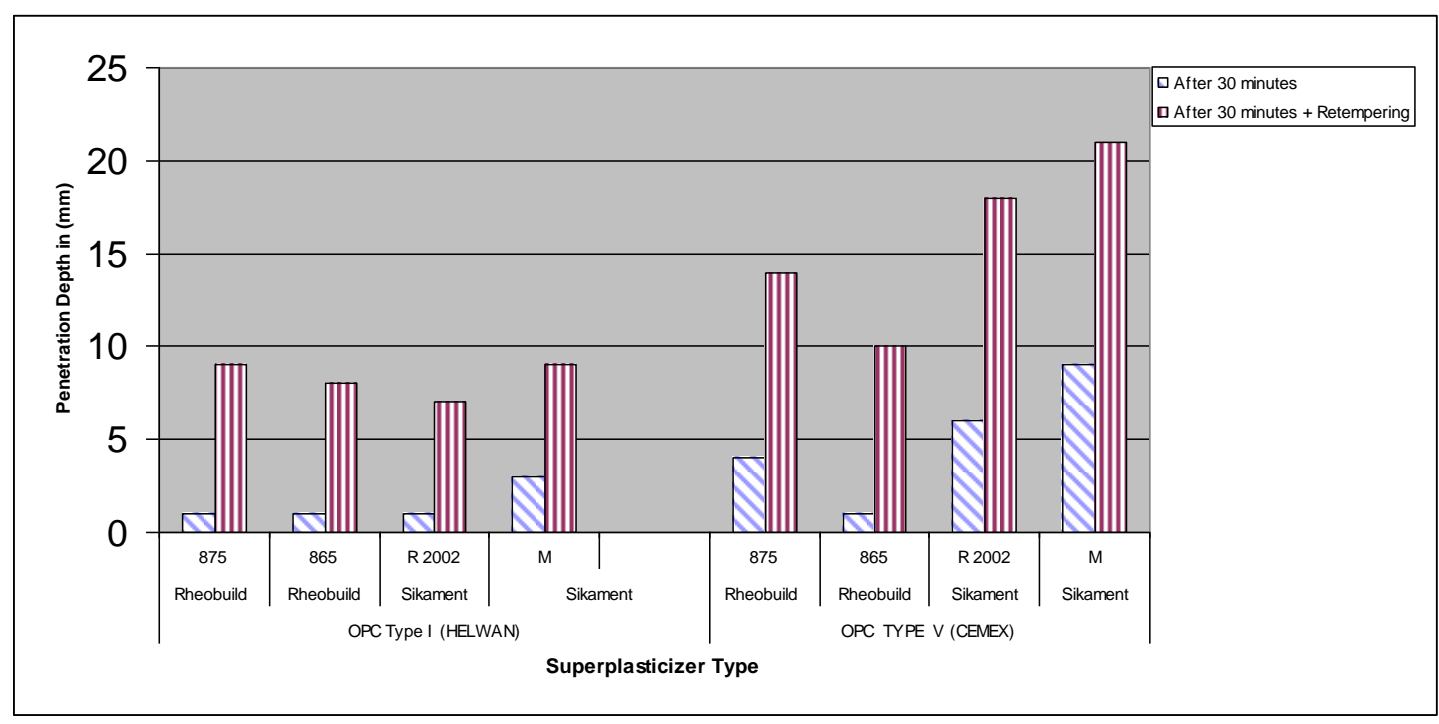

Fig ( 10) Effect of Retempering After 30 Minutes Retempering On OPC type(I) and SRC type (V)

\section{Effect of 5 minutes delay in addition of super plasticizer on penetration depth:}

For all subgroups at this stage, the penetration depth value at $\mathrm{P} / \mathrm{C}$ ratio of $0.8 \%$ was measured as we delayed addition of $14 \%$ by volume of mixing water with super plasticizer by 5 minutes after initial mixing.

Effect of 5 minutes delay in addition of super plasticizer on penetration depth of OPC Type I (Helwan) cement paste:

For Rheobuild 875 , the penetration depth value at $\mathrm{P} / \mathrm{C}$ ratio of $0.8 \%$ was $32 \mathrm{~mm}$. This value increased up to $46 \mathrm{~mm}$ as we added super plasticizer with $14 \%$ of mixing water after initial mixing which was less than the value of $51 \mathrm{~mm}$ at optimum dosage $1.2 \%$ incase of normal way of mixing. See Fig (11).

For Rheobuild 865 , at $\mathrm{P} / \mathrm{C}$ ratio of $0.8 \%$ was $26 \mathrm{~mm}$. Delay in addition of $14 \%$ by volume of the mixing water by 5 minutes resulted in increase in the penetration depth to $35 \mathrm{~mm}$, this value less than the $39 \mathrm{~mm}$ penetration value at optimum dosage $1.2 \%$. 
For Sikament R2002, the penetration depth value at $\mathrm{P} / \mathrm{C}$ ratio of $0.8 \%$ was $26 \mathrm{~mm}$. This value increased to $35 \mathrm{~mm}$ as we added super plasticizer with $14 \%$ by volume, of the mixing water after initial mixing which was less than the value of $41 \mathrm{~mm}$ at optimum dosage $1.2 \%$ incase of normal way of mixing.

For Sikament M, the penetration depth value at $\mathrm{P} / \mathrm{C}$ ratio of $0.8 \%$ was $27 \mathrm{~mm}$ while this value increased to $41 \mathrm{~mm}$ as we added super plasticizer with $14 \%$ of mixing water after initial mixing which was equal to the value of $41 \mathrm{~mm}$ at optimum dosage $1.1 \%$ incase of normal way of mixing.

\section{Effect of 5 minutes delay in addition of super plasticizer on penetration depth of SRC Type V (Cemex) cement paste:}

For Rheobuild 875 , the penetration depth value at $\mathrm{P} / \mathrm{C}$ ratio of $0.8 \%$ was $23 \mathrm{~mm}$. This value increased to $48 \mathrm{~mm}$ as we added super plasticizer with $14 \%$ of mixing water which was more than the value of $37 \mathrm{~mm}$ at optimum dosage $1.2 \%$ incase of normal way of mixing. This was contrary to the case where OPC was used. See Fig (11).

For Rheobuild 865 , the penetration depth value at $\mathrm{P} / \mathrm{C}$ ratio of $0.8 \%$ was $20 \mathrm{~mm}$. This value increased up to $38 \mathrm{~mm}$ as we added super plasticizer with $14 \%$ of mixing water after initial mixing which was more than the value of $26 \mathrm{~mm}$ at optimum dosage $1.1 \%$ incase of normal way of mixing.

For Sikament R2002, the penetration depth value at $\mathrm{P} / \mathrm{C}$ ratio of $0.8 \%$ was $24 \mathrm{~mm}$. This value increased to $43 \mathrm{~mm}$ as we added super plasticizer with $14 \%$ of mixing water after initial mixing which was also less than the value of $29 \mathrm{~mm}$ at optimum dosage $1.1 \%$ incase of normal way of mixing.

For Sikament $\mathrm{M}$, the penetration depth value at $\mathrm{P} / \mathrm{C}$ ratio of $0.8 \%$ was $15 \mathrm{~mm}$. This value increased to $45 \mathrm{~mm}$ as we added super plasticizer with $14 \%$ of mixing water after initial mixing which was more than the value of $32 \mathrm{~mm}$ at optimum dosage $1.1 \%$ incase of normal way of mixing. 


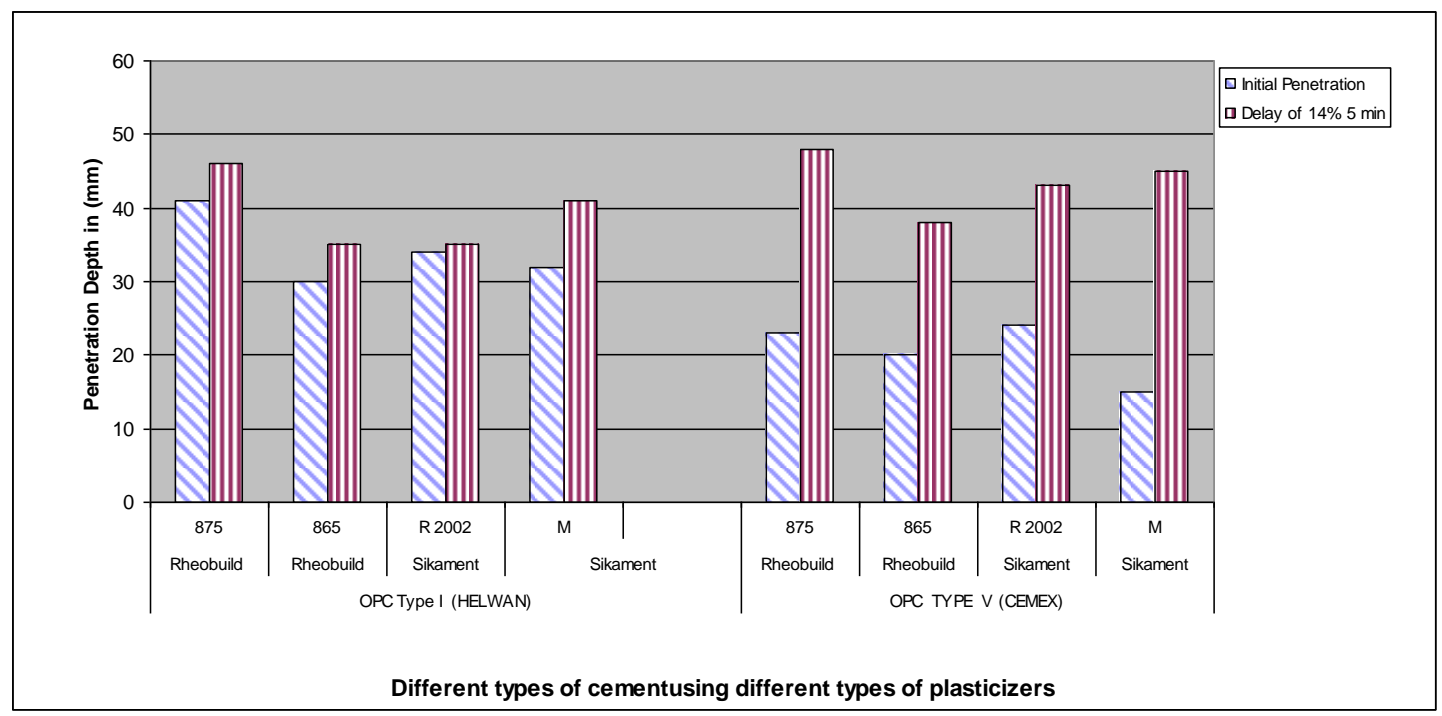

Fig (11) Effect of 5 minutes delay penetration depth

\section{Phase III}

\section{Effect of height of needle on penetration depth:}

For all subgroups in this study we will discuss the effect of different types of admixtures ( Rheobuild 875, Rheobuild 865, Sikament M, and Sikament R2002) on flow properties of cement paste (penetration depth), as mentioned previously, the water/cement under investigation was $(0.35,0.4,0.45,0.5$, and 0.55$)$ no plasticizer was used in this study.

\section{Effect of height of needle on penetration depth of OPC Type I (Helwan):}

For w/c ratio 0.35 , at $4 \mathrm{~cm}$ drop height of needle from surface of cement paste, the penetration depth was $14 \mathrm{~mm}$, this value increased to $16 \mathrm{~mm}$ as the height increased to $9 \mathrm{~cm}$ and reached a maximum value of $25 \mathrm{~mm}$ at height of $14 \mathrm{~cm}$. See Fig (12).

For w/c ratio of 0.4 , at $4 \mathrm{~cm}$ height of needle from surface of cement paste, the penetration depth was $28 \mathrm{~mm}$, this value increased to $34 \mathrm{~mm}$ as the height increased to $9 \mathrm{~cm}$ and reached the maximum value of $42 \mathrm{~mm}$ at height of $14 \mathrm{~cm}$.

For w/c ratio of 0.45 , at $4 \mathrm{~cm}$ height of needle from surface of cement paste, the penetration depth was $40 \mathrm{~mm}$, this value increased to $47 \mathrm{~mm}$ as the height increased to $9 \mathrm{~cm}$ and reached the maximum value of $62 \mathrm{~mm}$ at height of $14 \mathrm{~cm}$.

For w/c ratio of 0.5 , at $4 \mathrm{~cm}$ height of needle from surface of cement paste, the penetration depth was $45 \mathrm{~mm}$, this value increased to $53 \mathrm{~mm}$ as the height increased to $9 \mathrm{~cm}$ and reached the maximum value of $64 \mathrm{~mm}$ at height of $14 \mathrm{~cm}$. For w/c ratio of 0.55 , at $4 \mathrm{~cm}$ height of needle from surface of cement paste, the penetration depth value was $55 \mathrm{~mm}$, this value increased to $64 \mathrm{~mm}$ as the height increased to $9 \mathrm{~cm}$ and reached the 
maximum value of $69 \mathrm{~mm}$ at height of $14 \mathrm{~cm}$. The general trend indicates that , for the same w/c ratio, as the height of needle increases, the penetration depth value of needle increases, also at the same height of needle, as the w/c ratio increases the penetration depth value. The relation between penetration depth and height of needle approximately a straight.

\section{Effect of height of needle on penetration depth of SRC Type V (Cemex) :}

For w/c ratio of 0.35 , at $4 \mathrm{~cm}$ height of needle from surface of cement paste, the penetration depth value was $14 \mathrm{~mm}$, this value increased to $17 \mathrm{~mm}$ as the height increased to $9 \mathrm{~cm}$ and reached the maximum value of $22 \mathrm{~mm}$ at height of $14 \mathrm{~cm}$. See Fig (12). For w/c ratio of 0.4 , at $4 \mathrm{~cm}$ height of needle from surface of cement paste, the penetration depth value was $25 \mathrm{~mm}$, this value increased to $29 \mathrm{~mm}$ as the height increased to $9 \mathrm{~cm}$ and reached the maximum value of $35 \mathrm{~mm}$ at height of $14 \mathrm{~cm}$.

For w/c ratio of 0.45 , at $4 \mathrm{~cm}$ height of needle from surface of cement paste, the penetration depth value was $50 \mathrm{~mm}$, this value increased to $55 \mathrm{~mm}$ as the height increased to $9 \mathrm{~cm}$ and reached the maximum value of $60 \mathrm{~mm}$ at height of $14 \mathrm{~cm}$. For w/c ratio of 0.5 , at $4 \mathrm{~cm}$ height of needle from surface of cement paste, the penetration depth value was $56 \mathrm{~mm}$, this value increased to $63 \mathrm{~mm}$ as the height increased to $9 \mathrm{~cm}$ and reached the maximum value of $67 \mathrm{~mm}$ at height of $14 \mathrm{~cm}$. For w/c ratio of 0.55 , at $4 \mathrm{~cm}$ height of needle from surface of cement paste, the penetration depth value was $63 \mathrm{~mm}$, this value increased to $68 \mathrm{~mm}$ as the height increased to $9 \mathrm{~cm}$ and reached the maximum value of $72 \mathrm{~mm}$ at height of $14 \mathrm{~cm}$.

The general trend indicates that, for the same w/c ratio, as the height of needle increases, the penetration depth value of needle increases, also at the same height of needle, as the w/c ratio increases the penetration depth value increases where the maximum penetration depth of value $72 \mathrm{~mm}$ was obtained at w/c ratio of 0.55 and height of $14 \mathrm{~cm}$, also the relation between penetration depth and height of needle approximately a straight line. 


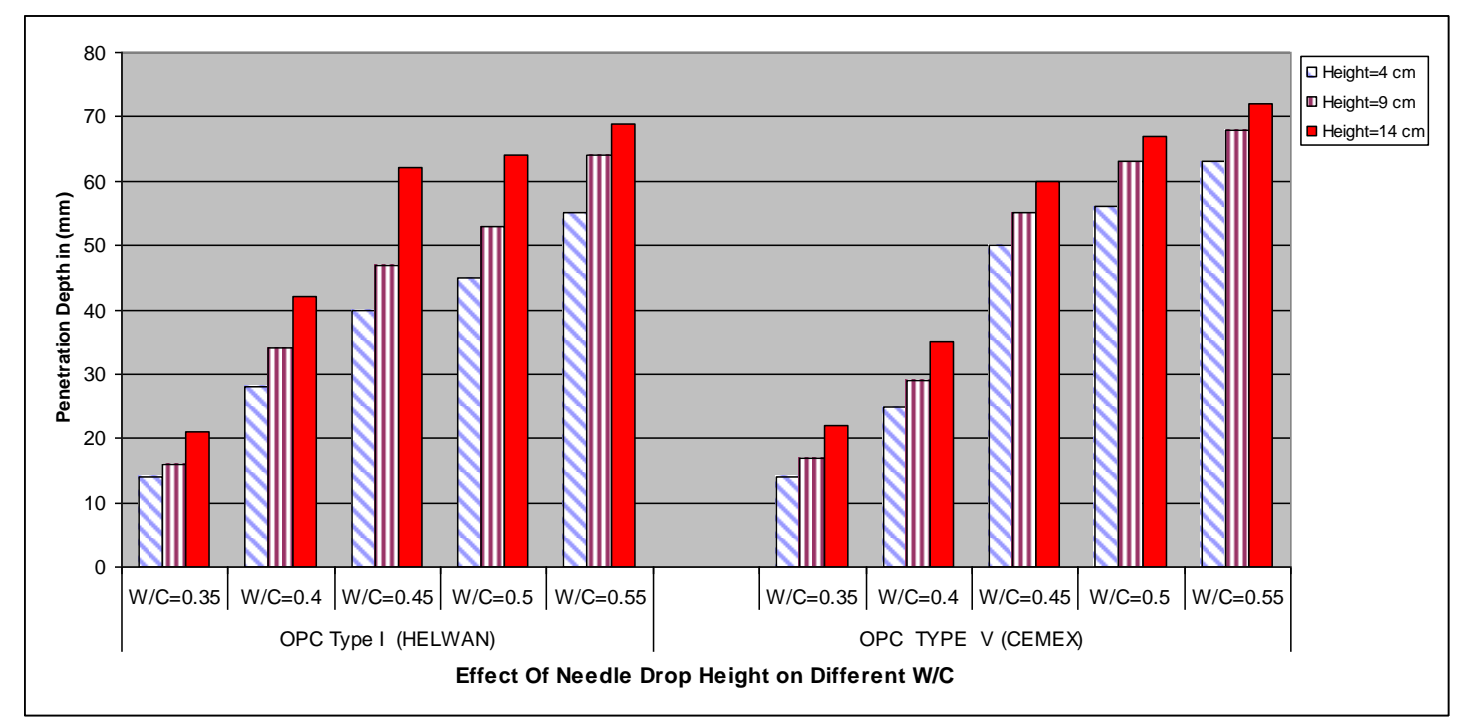

\section{Fig (12) Effect of height of needle on penetration depth}

\section{Conclusion}

Introduction:

In this study the rheological behavior of fresh cement paste containing chemical admixtures and cement replacement materials for several types of cement was discussed, this was followed by a briefing on the experimental program \& the testing techniques, finally presentation and analysis of results will be discussed to conclude in this work.

\section{Phase I}

1- It is evident that the penetration depth technique adopted in this study was successful in determining the optimum point where penetration reaches the maximum value.

2- The penetration depth technique proved to be effective in monitoring the effect of percent dosage of chemical admixtures on the rheological behavior of different types of cement paste.

3- Investigation of the effect of w/c ratio on the rheological behavior of different types of cement showed that as the w/c ratio increases, the penetration depth increases,

Phase II

4- It was noted that the technique proved to be successful in monitoring the effect of time on the rheological behavior of different types of cement, for all types of cement, it was noted that as the time increases, the penetration depth decreases.

5- It was noted that agitation of cement paste manually after 30 minutes of water addition proved to be effective in the break down structure of the cement paste and increasing the penetration depth once more. 
6- The effect of delay in addition of chemical admixture with $30 \%$ of the mixing water proved to be very effective in increasing the penetration depth in all subgroups.

Phase III

7- It was noted that as the height of the needle increases, the penetration depth for all types of cement increases.

\section{References:}

1 Russell H. G., "ACI Defines High-Performance Concrete" Concrete International vol. 21, [2] (1999).

2 Beaupré D., Mindess S., "Rheology of Fresh Concrete: Principles, Measurements, and Applications", Materials Science of Concrete V, Ed. by J. Skalny and S. Mindess, Acers, 149-190,(1998)

3 Ferraris C.F., "Measurements of Rheological Properties of High Performance Concrete: State of the Art Report", NIST-IR 5869, (1996).

4 Ferraris, C. F., "Measurement of the Rheological Properties of High Performance Concrete: State of the Art Report", Journal of Research of NIST, 105 (5), 461-478 (1999)

5 Hopkins, C.J., Cabrera, J.G., "The Turning-Tube Viscometer: an Instrument to Measure the Flow Behavior of Cement-pfa Pastes", Mag. of Concrete Research 37, 101109 (1985)

$6 \mathrm{Hu}, \mathrm{C}$. , de Larrard F., Gjørv O., "Rheological Testing and Modelling of Fresh High Performance Concrete", RILEM, Mat. and Structures, vol. 28, 1-7 (1995)

7 De Larrard, F., Hu C., Szitkar, J.C., Joly, M., Claux, F.and Sedran, T., "A New Rheometer for Soft-to-Fluid Fresh Concrete", LCPC internal report (1995)

8 Ferraris, C. F. , de Larrard, F., "Modified Slump Test to Measure Rheological Parameters of Fresh Concrete", ASTM Cement, Concrete and Aggregates, 20 [2], 241247, (1998)

9 Ferraris F., Gaidis J., "Connection Between the Rheology of Concrete and Rheology of Cement Paste", ACI Materials Journal, 89, No.4, 388-393, (1992)

10 Struble L.J., Sun G.K., "Cement Viscosity as a Function of Concentration" in Flow and Microstructure of Dense Suspensions, Ed. by Struble, Zukoski and Maitland, Materials Research Society (MRS), Symposia Proc., Pittsburgh MRS, 289 173-178, (1993)

11 Kim H., Park Y.-D., Noh J., Song Y., Han C. and Kang S., "Rheological Properties of Self-Compacting, High-Performance Concrete" , Third Int. ACI Conf. Proc. on HighPerformance Concrete: Design and Materials and Recent Advances in Concrete Technology, Ed. by Malhotra, SP-172, 653-668, (1997)

12 Shindoh T., Yokota K., Yokoi K., "Effect of Mix Constituents on Rheological Properties of Super Workable Concrete", Proc. of RILEM Int. Conf. Production 
Methods and Workability of Concrete, Ed. Bartos P.J.M., Marrs D.L. and Cleland D.J. Scotland 263-270, (1996).

13 Nagataki S., "Present State of Superplasticizers in Japan", Int. Symp. On Mineral and Chemical Admixtures in Concrete, Toronto (Canada) April (1998).

14 Sakata N., Maruyama K., Minami M., "Basic Properties and Effects of Welan Gum on Self-Consolidating Concrete", Proc. of RILEM Int. Conf. Production Methods and Workability of Concrete, Ed. Bartos P.J.M., Marrs D.L. and Cleland D.J. Scotland, 237253, (1996).

15 Nkinamubanzi P.-C., Baalbaki M. and Aïtcin P.-C., "Comparison of the Performance of Four Superplasticizers on High Performance Concrete", Proceedings of the Fifth CANMET/ACI International Conference on Superplasticizers and other Chemical Admixtures in Concrete, Rome, Italy, October 7-10, 1997 (Supplementary Papers). 16 Kuroiwa, S., Matsuoka, Y., Hayakawa, M. and Shindoh, T., "Application of Super Workable Concrete to Construction of a 20-Story Building", High Performance Concrete in Severe Environments, Ed. by Paul Zia, ACI SP-140, 147-161 1993

17 Miura, N., Takeda N., Chikamatsu, R., Sogo, S., "Application of Super Workable Concrete to Reinforced Concrete Structures with Difficult Construction Conditions", High Performance Concrete in Severe Environments, Ed. by Paul Zia, ACI SP-140, 163186 (1993). 